\title{
Quo Vadis 2010? - Carpe Diem: Challenges and Opportunities in Pediatric Traumatic Brain Injury
}

\author{
Patrick M. Kochanek ${ }^{\mathrm{a}, \mathrm{b}}$ Michael J. Bell ${ }^{\mathrm{a}-\mathrm{c}}$ Hülya Bayır ${ }^{\mathrm{a}-\mathrm{c}}$

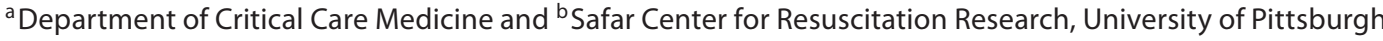 \\ School of Medicine, and 'Children's Hospital of Pittsburgh, Pittsburgh, Pa., USA
}

\section{Key Words}

Traumatic brain injury $\cdot$ Head injury $\cdot$ Head trauma $\cdot$

Child abuse $\cdot$ Biomarker $\cdot$ Imaging $\cdot$ Treatment

\begin{abstract}
Traumatic brain injury (TBI) in infants and children remains a public health problem of enormous magnitude. It is a complex and heterogeneous condition that presents many diagnostic, therapeutic and prognostic challenges. A number of investigative teams are studying pediatric TBI both in experimental models and in clinical studies at the bedside. This review builds on work presented in a prior supplement to Developmental Neuroscience that was published in 2006, and addresses several active areas of research on this topic, including (1) the application of novel imaging methods, (2) the use of serum and/or CSF biomarkers of injury, (3) advances in neuromonitoring, (4) the development and testing of novel therapies, (5) developments in modeling pediatric TBI, (6) the consideration of a new approach to classification of pediatric TBI, and (7) assessing the potential impact of the development of pediatric and neonatal neurocritical care services on the management and outcome of pediatric TBI.
\end{abstract}

Copyright $\odot 2011$ S. Karger AG, Base

\section{KARGER}

Fax +41613061234 E-Mail karger@karger.ch www.karger.com
(C) 2011 S. Karger AG, Basel

$0378-5866 / 10 / 0326-0335 \$ 26.00 / 0$

Accessible online at:

www.karger.com/dne

\section{Introduction}

In 2006, Developmental Neuroscience published its first supplement devoted to the topic of pediatric traumatic brain injury (TBI). That endeavor, assembled and edited by Drs. Mary McKenna and Courtney Robertson, produced a highly successful collection of articles in the field that spanned the range from basic to clinical investigation. The field was ready for such a supplement, and its timing coincided with a period of considerable growth both in this area of research and in the emerging subspecialty of pediatric neurocritical care. Several of the reports in that issue have become well-cited works, and it is likely not a coincidence that the most highly cited articles addressed some of the hot-button areas of investigation in TBI [1-5]. This review is part of a new second supplement on this topic published in Developmental Neuroscience. Several of the articles from the original review serve as the backdrop to identify important areas of investigation in pediatric TBI and some of the directions where the field is heading. Some of the most important challenges and opportunities that we face in this field are identified. Finally, how many of the studies that are included in this new 2010 supplement begin to address these challenges is discussed. 


\section{Imaging}

Ashwal et al. [1] published an outstanding article on new imaging modalities in pediatric TBI in the 2006 supplement that represented the second most highly cited work from that issue. It is clear that advances in magnetic resonance imaging (MRI) and MR spectroscopy are catapulting forward our understanding of this extremely complex disease. New modalities such as susceptibilityweighted imaging can enhance the detection of even small hemorrhages in parenchyma, while diffusion tensor imaging allows us to serially map diffuse injury to white matter tracks in pediatric TBI. The latter was a topic that was identified as being of considerable potential importance in the 2006 supplement in an article by Robert Tasker [6]. As with novel MRI modalities, MR spectroscopy also provides, in our critically injured patients, enlightening and detailed maps of key metabolites in injured brain, such as lactate, $\mathrm{N}$-acetylaspartate, choline and glutamine [1] - linking anatomical and biochemical data in the injured brain of infants and children. Somewhat more futuristic MRI methods such as cell tracking have the potential to facilitate the in vivo monitoring of processes such as the inflammatory response and apoptosis in TBI [7-9]. In this issue, an article on the utility of clinical imaging in pediatric TBI addresses the important issues of abusive head trauma [10]. Also, Wu et al. [11] studies atrophy and remodeling of the corpus callosum in 48 children with mild-to-moderate TBI using diffusion tensor imaging. Without a doubt, the study of axonal injury via diffusion tensor imaging and other MRI methods has great potential to aid in defining a critical target - white matter damage - that deserves more attention in TBI. An additional discussion of axonal injury in pediatric TBI is found later in this review. The potential for novel imaging and spectroscopic methods cannot, in our opinion, be overestimated.

\section{Biomarkers}

The other area of investigation published on in the 2006 Developmental Neuroscience supplement that garnered considerable attention was work on biomarkers of brain injury. Several reports suggested that biomarkers might be valuable in pediatric TBI $[2,5,12-20]$. The most highly cited article from the supplement, by Dr. Rachel Berger et al. [2], serially assessed three serum biomarkers [neuron-specific enolase (NSE), S100B and myelin basic protein (MBP)] across three diseases in the pediatric in- tensive care unit (PICU), namely TBI, abusive head trauma and cardiopulmonary arrest. The report indicated that the biomarker profiles across these three diseases appear to be different, both with regard to timing and marker composition. Early neuronal death was seen after TBI, presumably from necrosis, while delayed neuronal death, possibly via apoptotic or other pathways, occurred in a number of the cardiac arrest victims. This suggests potential mechanistic and therapeutic ramifications. Recently, Topjian et al. [12] reported similar increases in serum levels of NSE and suggested a threshold level of $51 \mu \mathrm{g} / \mathrm{l}$ for predicting unfavorable outcome. In the 2006 supplement, a report by Aikman et al. [21] assessed calpain versus caspase cleavage products of $\alpha$-spectrin in an experimental model of developmental TBI, under the premise that the former reflects cell death from necrosis, while the latter reflects cell death from apoptosis. They showed that although both pathways were present, calpain proteolysis predominated. Recent work by Brophy et al. [22], assessing serial CSF samples from adults with severe TBI, compared calpain versus caspase cleavage products of $\alpha$-spectrin and also suggested that necrosis may predominate in TBI since, despite marked early increases in calpain cleavage products in CSF, there were only low levels of caspase cleavage products. These findings certainly do not exclude the possibility that apoptotic neuronal death plays a role in the evolution of secondary damage in pediatric TBI, and it may be that, temporally, earlier biomarkers of apoptosis such as cardiolipin oxidation products are more specific than caspase activity [23]. One patient group that may have considerable apoptotic neuronal death, for example, are victims of abusive head trauma since they showed a similar NSE profile to pediatric cardiac arrest victims, with delayed increases in serum levels, in the report by Berger et al. [2]. An important role for hypoxic-ischemic injury in abuse cases has also been suggested by the work of Ichord et al. [24], using MRI. A similar pattern might be anticipated in infants with noninflicted TBI, where developmental propensity to apoptosis may influence cell death mechanisms. Nevertheless, cell death mechanisms such as necrosis and autophagy merit special focus as we move forward in the field.

Relevant to TBI, in the report by Berger et al. [2], delayed increases in serum levels of MBP were also seen, but only in victims of TBI and abuse, not in cardiac arrest. This suggests that delayed axonal damage might represent a potential therapeutic target in both forms of TBI. A key question in this regard is whether this increase in MBP represents delayed axotomy, related to calcium ac- 
cumulation and calpain proteolysis, as suggested by Povlishock and Christman [25], or simply axonal lysis secondary to wallerian degeneration. The former would represent a potentially important therapeutic target in TBI, while the latter would simply reflect remodeling of tissue where neurons were already lost. The role of axonal injury and fiber track damage as potential targets in pediatric TBI deserves additional study. The delayed time course of this process suggests a broad therapeutic window and thus a potential opportunity for treatment.

A study published in the 2006 supplement from the laboratory of Dr. Larry Jenkins [5] on experimental controlled cortical impact injury in developing rats linked bench and bedside on the topic of biomarkers and used proteomics (2-D gel) to reveal that mitochondrial injury, oxidative stress and astrocyte proliferation represent three important mechanistic opportunities in pediatric TBI. Additional basic and clinical investigation has supported and embellished those findings [26-29]. Germane to this work, a new clinical study by Fraser et al. [30] suggested that the astrocyte marker glial fibrillary acidic protein may be a robust brain injury biomarker in pediatric TBI. Proteomic and related assessments of serum and CSF may provide additional insight into understanding of secondary injury mechanisms, define therapeutic targets, predict outcome and/or aid in patient selection for clinical trials. Biomarker work needs to be coupled to new MRI methods in future studies. Given the critical need for better diagnostic tools in mild TBI in conditions such as sports concussion and blast injury in terrorist attacks and/or combat casualty care, the field of biomarkers in brain injury has been an extremely active area of research. In this new supplement, several studies on biomarkers in pediatric TBI build on the work in this area of investigation $[31,32]$.

\section{Advanced Neuromonitoring}

The use of advanced neuromonitoring approaches in pediatric TBI has been another area of considerable research in pediatric TBI, and one of the leaders in this area, Monica Vavilala, published a report on the assessment of blood pressure autoregulation of cerebral blood flow $(\mathrm{CBF})$ and its relationship to outcome in pediatric TBI in the 2006 supplement [3]. Using bedside Doppler assessments, Dr. Vavilala's study has demonstrated how common loss of blood pressure autoregulation is, in pediatric TBI, being seen in over $40 \%$ of cases, and highly associated with an unfavorable 6-month Glasgow outcome scale score. Subsequent studies by her group also demonstrated loss of blood pressure autoregulation of CBF in infants who are victims of abusive head trauma [33]. Several investigators in pediatric TBI have championed various bedside monitoring approaches. Most noteworthy among them is the continuous bedside monitoring of the pressure-reactivity index, which assesses CBF autoregulation based on the relationship between arterial blood pressure and intracranial pressure (ICP) in pediatric TBI [34]. Spearheaded for use in children by Ken Brady at Johns Hopkins, this intriguing work suggests that one might be able to better define optimal cerebral perfusion pressure (CPP) in pediatric TBI victims at the bedside - a very worthy therapeutic goal. Factors such as the regional nature of the injury in TBI, however, magnify the challenges to interpretation of the findings by such an approach. Nevertheless, this represents an interesting potential opportunity and merits further study. Another monitoring modality that has important potential for future use and study is brain tissue oxygen $\left(\mathrm{PbO}_{2}\right)$ monitoring. Reports on the use of this modality in pediatric TBI are somewhat limited [35], but several outstanding studies in adult patients with severe TBI have begun to better define its utility $[36,37]$. This topic garnered an entire chapter in the most recent edition of the guidelines for the management of severe TBI in adults [38]. Its greatest potential role is likely to be in augmenting the titration of ICP - directed care at the bedside - optimizing a second physiologically relevant target. For example, there are some patients with normal ICP but concerning levels of $\mathrm{PbO}_{2}$, and in that setting, improving this parameter may translate into improved outcomes if the relationship between critical thresholds for $\mathrm{PbO}_{2}$ and outcomes represents more than an association or epiphenomenon.

Although we target the prevention of tissue hypoxia to prevent secondary injury in the PICU management of patients with severe TBI, hyperoxia may also be detrimental. Related to this area of investigation, seminal work from the laboratory of Dr. Gary Fiskum [39] has demonstrated that hyperoxic resuscitation in adult animal models of cardiac arrest have deleterious consequences - likely via protein nitration of key enzymes such as pyruvate dehydrogenase (PDH) [40]. Curiously, in the aforementioned proteomic study of experimental TBI [5], PDH was one of the proteins that demonstrated the greatest loss at 2 weeks after controlled cortical impact in the developing rat brain. However, a recent exploratory study by Puccio et al. [41] was not able to demonstrate increases in CSF levels of markers of oxidative stress in adults with severe TBI exposed to $100 \%$ oxygen. Given the compromised 
antioxidant defenses in the developing brain, with enhanced vulnerability to hydrogen peroxide [42], this area merits additional study in pediatric TBI. This finding has now been translated to the human condition, where hyperoxia is associated with poor outcome after cardiac arrest in adults [43, 44].

A second important gap in knowledge with regard to neuromonitoring in pediatric TBI is addressed in this supplement by the report by Mehta et al. [45], namely ICP and CPP assessment in infants with severe TBI. The eyeopening study by Keenan et al. [46] reported that ICP monitoring in children less than 2 years of age with severe TBI in the state of North Carolina was only performed in $33 \%$ of cases and defined an important concern in the field. Similarly, even the important recent study of critical ICP and CPP thresholds by Chambers et al. [47] from the UK multicenter pediatric TBI database did not include infants. Given the well-described poor outcomes of this extremely vulnerable subgroup of pediatric TBI from the early work by Levin et al. [48], the report by Mehta et al. [45] is a welcome exploratory one.

\section{Therapy}

In the 2006 supplement, Jamie Hutchison and his investigative team [49] described the pretrial evaluation phase of what ultimately was to be their important multicenter trial of mild hypothermia in pediatric TBI. Without question, the most disappointing development since the publication of the last supplement is the failure of mild hypothermia to show efficacy in the landmark Canadian multicenter clinical trial. Despite the failure of hypothermia, a great deal was learned from that trial, and more is likely to be learned as all of us continue to ponder the findings. Hypotension, particularly during rewarming, appeared to represent a critical toxicity of hypothermia in the trial [49], and this important issue is the focus of a report by Dr. Hutchison et al. [50] in this issue. This side effect has been reported with variable frequency in other trials or applications of hypothermia in adult or pediatric brain injury. For example, it was observed in the multicenter TBI trial in adults that was carried out by Dr. Guy Clifton et al. [51]. In contrast, it did not appear to represent a major problem in the report by Marion et al. [52], or in the large Chinese experience with hypothermia in adult TBI $[53,54]$. Although one may argue about various aspects of the study design of the Hutchison trial [50], it represents the most important study in the history of pediatric TBI and identifies some additional points that merit discussion. First, these findings in pediatric TBI had emerged shortly before the 3rd International Hypothermia Symposium in Lund, where the results of two additional studies on adult TBI were reported: the second multicenter NIH-funded trial by Dr. Clifton [55] and the Japanese multicenter trial led by Professor Tsuyoshi Maekawa [56]. Neither of these trials demonstrated a benefit of mild hypothermia, the former being stopped for futility, while the latter showed nearly identical outcomes between groups. Thus, despite proven effects on ICP, among others in two carefully controlled studies in children $[57,58]$, this therapy does not appear to improve functional outcomes in pediatric TBI when used as applied in the trials.

Curiously, exciting positive data have emerged on beneficial effects of mild hypothermia on perinatal asphyxia of term newborns, including work in three separate multicenter trials [59-61]. Hypothermia also attenuated structural brain injury as assessed by MRI in the most recent of these trials [62]. The question of why mild hypothermia would be efficacious in perinatal asphyxia but ineffective in pediatric TBI is an important one, and there are many potential explanations. One is certainly that a substantive number of brain-directed therapies and monitoring are provided as part of standard of care in pediatric TBI, while there is little or no brain-directed monitoring and care for cardiac arrest victims. Thus, in TBI, use of hypothermia may simply represent a trading of therapies. For example, less hypertonic saline might be used in lieu of cooling, and the net benefit could be greatly diminished. In contrast, hypothermia is used as the sole neuroprotective strategy in perinatal asphyxia, other than the occasional use of anticonvulsants for hypoxic seizures. Some insight into the potential efficacy of hypothermia in TBI versus perinatal asphyxia could also relate to the aforementioned work by Berger et al. [2], published in the 2006 Developmental Neuroscience supplement. If the serum biomarker data in that report reflect changes in brain parenchyma, victims of asphyxial cardiac arrest may have considerably more delayed neuronal death than TBI victims. Thus, the resuscitation targets for TBI may be different, or require extremely early intervention. A number of other potential explanations for the differential efficacy of hypothermia in pediatric neurocritical care have been posed, and this topic is discussed in greater detail in another recent review [63]. Hypothermia is still under investigation in pediatric TBI in the Pediatric Traumatic Brain Injury Consortium - Hypothermia trial, led by Dr. David Adelson, and several reports in this supplement address various hypothermia-related issues in pediatric TBI $[31,50]$. 
An emerging area of therapeutic investigation in pediatric TBI is the manipulation of the regenerative response to TBI either via modulation of neurogenesis or treatment with stem cells. Dr. Steve Kernie's masterpiece plenary presentation on this topic at the 2009 joint Congress of the National and International Neurotrauma Societies reviewed some of his recent work, showing that neuroblasts in the dentate gyrus are vulnerable after experimental TBI, along with the potential role of hippocampal neurogenesis in improving cognitive outcomes [64]. Related to this topic is a report by Covey et al. [65] on temporal factors in neurogenesis in brain injury. In addition, Wright et al. [66] present an elegant study examining the role of cortical progenitor cells in oligodendrogenesis and the critical contribution of these cells in myelination during development. Cell-based therapies are an important therapeutic opportunity that may have merit along the continuum of care from the ICU through to rehabilitation.

With regard to novel pharmacological approaches to pediatric TBI, Scafidi et al. [67] present data supporting the potential of using acetyl-L-carnitine to target mitochondrial failure after experimental TBI in developing rats (postnatal day 21-22). The rationale behind this strategy is based on a large body of work from the laboratory of Dr. Gary Fiskum [68, 69] and others [5] supporting the posttranslational modification and inhibition of activity of the PDH enzyme complex after both traumatic and ischemic insults. PDH appears to be highly sensitive to oxidative injury, which could thus have special implications for the developing brain, given its limited antioxidant defenses.

\section{Modeling}

Better modeling of pediatric TBI is essential to the development of new therapies. Currently, controlled cortical impact in developing rats and/or mice has been used for many of the experimental studies $[5,43]$. This likely models only a portion of the spectrum of pediatric TBI, as pointed out by Duhaime [70] in the 2006 supplement. In this issue, work from the laboratory of Dr. Susan Margulies by Naim et al. [71] is presented, using a new and exciting model of rotational TBI in developing piglets. Dr. Kochanek had the good fortune of visiting her laboratory and was extremely impressed at how this model captures many of the PICU-relevant features of severe TBI including meaningful intracranial hypertension and critical reductions in $\mathrm{PbO}_{2}$. In this issue of Developmental Neuro- science, her group presents some exciting new data on the use of folic acid as a novel therapy. This model represents a valuable opportunity to go up the phylogenetic tree and study a gyrencephalic animal closer to man. Also in this issue, Prins et al. [72] report on the development of a repeated injury model of TBI in juvenile rats, and Cernak et al. [73] present the characterization of a new developmental model of diffuse TBI. Similarly, the article by Babikian et al. [74] focuses on developmental issues related to metabolism and growth, and Claus et al. [75] address developmental aspects of neuroinflammation, both of which reveal important age-related differences that may direct the development of new therapies. These represent important areas for new model development and investigation in experimental pediatric TBI. Finally, again in this issue, Robert Tasker's group [76] highlights the potential importance of axonal injury as a therapeutic target in pediatric TBI.

\section{Classification}

Another interesting area of study in TBI is the topic of improving its tools for classification. The Glasgow Coma Scale (GCS) score has served the field for many years, but provocative work by Dr. Geoff Manley has suggested that to be able to achieve success in clinical trials, a new system of classification is called for. Geoff uses, in his presentations on this topic, a clever slide that shows six very different cranial CT scans of adult patients including a contusion, an epidural hematoma, a subdural hematoma, diffuse swelling, diffuse axonal injury and subarachnoid hemorrhage, and indicates that they represent 'six ways to get to a GCS score of 4'. He has suggested each of these insults may actually represent different diseases and that they will require separate therapeutic regimens. He suggests that how we are currently approaching treatment of TBI would equate to attempting to treat all forms of cancer with a single therapeutic approach. He may indeed be correct, and the situation may be even more complex in pediatric TBI. In pediatric TBI, there is another important CT pattern to layer upon this six-scan CT paradigm, namely abusive head trauma. It was beautifully demonstrated in the prior supplement, in work by Berger et al. [2] and in a recent supplement to the Journal of $\mathrm{Neu}$ rotrauma focused on inflicted childhood neurotrauma in work by Ichord et al. [24], that abusive head trauma represents a separate clinical entity. This appears to be true both from the standpoint of biomarker profile and findings on MRI, respectively. Clearly, limitations of the cur- 
rent TBI classification by GCS could be a critical limiting factor for the success of any treatment trial, as suggested by the work of Shore et al. [15], and it may be that specific therapies such as osmolar agents versus hypothermia, for example, would have different efficacy in a specific subgroup of TBI patients, such as contusion versus diffuse swelling. Many of the papers in this supplement interface with this concept, which may represent a key challenge to and opportunity for the entire field of TBI.

\section{Neurocritical Care}

Finally, several articles in this supplement address the topic of neurocritical care in pediatric TBI, notably a report by di Gennaro et al. [77] on vasopressor use, among others. There is considerable interest in the development of specialized neurocritical care services or even neurocritical care units for infants and children. To my knowledge, only a few programs exist: at the Children's Hospital of Pittsburgh, Children's Memorial Hospital and Children's National Medical Center for pediatric neurocritical care, and at the University of California San Francisco for neonatal neurocritical care. Such teams should support the highest possible standard of monitoring and care and contribute state-of-the-art clinical research $[78,79]$. This exciting concept is discussed for pediatric critical care in a report by Bell et al. [80] and, for neonates, in a recent report by Glass et al. [81]. Collaborative teams in neurocritical care that link bench and bedside across the multidisciplinary specialties such as critical care medicine, child neurology, emergency medicine, neurosurgery, pediatrics, physical medicine and rehabilitation, and radiology, among others, represent a tremendous opportunity to better understand pediatric TBI, prevent secondary insults, aid in the development and implementation of new therapies, and improve outcomes. Our sense is that such services would also have an important trickle-down effect by improving care in mild and moderate TBI patients who do not need ICU services. This supplement to Developmental Neuroscience supports that notion, given the fact that it addresses aspects of pediatric TBI from bench to bedside and across the injury severity spectrum.

\section{Acknowledgments}

Work on this review was supported in part by NS30318. We thank Cara Boyer, Fran Mistrick and Marci Provins for their assistance with manuscript preparation.

\section{References}

1 Ashwal S, Holshouser BA, Tong KA: Use of advanced neuroimaging techniques in the evaluation of pediatric traumatic brain injury. Dev Neurosci 2006;28:309-326.

-2 Berger RP, Adelson PD, Richichi R, Kochanek PM: Serum biomarkers after traumatic and hypoxemic brain injuries: insight into the biochemical response of the pediatric brain to inflicted brain injury. Dev Neurosci 2006;28:327-335.

- 3 Vavilala MS, Muangman S, Tontisirin N, Fisk D, Roscigno C, Mitchell P, Kirkness C, Zimmerman JJ, Chesnut R, Lam AM: Impaired cerebral autoregulation and 6-month outcome in children with severe traumatic brain injury: preliminary findings. Dev Neurosci 2006;28:348-353.

4 Bayır H, Kochanek PM, Kagan VE: Oxidative stress in immature brain after traumatic brain injury. Dev Neurosci 2006;28:420431.

5 Kochanek AR, Kline AE, Gao WM, Chadha M, Lai Y, Clark RSB, Dixon CE, Jenkins LW: Gel-based hippocampal proteomic analysis 2 weeks following traumatic brain injury to immature rats using controlled cortical impact. Dev Neurosci 2006;28:410-419.
-6 Tasker RC: Changes in white matter late after severe traumatic brain injury in childhood. Dev Neurosci 2006;28:302-308.

7 Zhao M, Beauregard DA, Loizou L, Davletov B, Brindle KM: Non-invasive detection of apoptosis using magnetic resonance imaging and a targeted contrast agent. Nat Med 2001;7:1241-1244.

$\checkmark 8$ Ye Q, Wu YL, Foley LM, Hitchens TK, Eytan DF, Shirwan H, Ho C: Longitudinal tracking of recipient macrophages in a rat chronic cardiac allograft rejection model with noninvasive magnetic resonance imaging using micrometer-sized paramagnetic iron oxide particles. Circulation 2008;118:149-156.

-9 Foley LM, Hitchens TK, Ho C, Janesko-Feldman KL, Melick JA, Bayır H, Kochanek PM: Magnetic resonance imaging assessment of macrophage accumulation in mouse brain after experimental traumatic brain injury. J Neurotrauma 2009;26:1509-1519.

10 Ashwal S, Wycliffe ND, Holshouser BA: Advanced neuroimaging in children with nonaccidental trauma. Dev Neurosci 2010; 32:343-360.
11 Wu TC, Wilde EA, Bigler ED, Li X, Merkley TL, Yallampalli R, McCauley SR, Schnelle KP, Vasquez AC, Chu Z, Hanten G, Hunter JV, Levin HS: Longitudinal changes in the corpus callosum following pediatric traumatic brain injury. Dev Neurosci 2010; 32:361-373

$\checkmark 12$ Topjian AA, Lin R, Morris MC, Ichord R, Drott H, Bayer CR, Helfaer MA, Nadkarni V: Neuron-specific enolase and S-100B are associated with neurologic outcome after pediatric cardiac arrest. Pediatr Crit Care Med 2009;10:479-490.

13 Haqqani AS, Hutchison JS, Ward R, Stanimirovic DB: Protein biomarkers in serum of pediatric patients with severe traumatic brain injury identified by ICAT-LC-MS/MS. J Neurotrauma 2007;24:54-74.

14 Gao WM, Chadha MS, Berger RP, Omenn GS, Allen DL, Pisano M, Adelson PD, Clark RS, Jenkins LW, Kochanek PM: A gel-based proteomic comparison of human cerebrospinal fluid between inflicted and non-inflicted pediatric traumatic brain injury. J Neurotrauma 2007;24:43-53. 
15 Shore PM, Berger RP, Varma S, Janesko KL, 26 Opii WO, Nukala VN, Sultana R, Pandya JD, Wisniewski SR, Clark RSB, Adelson PD, Thomas NJ, Lai YC, Bayır H, Kochanek PM: Cerebrospinal fluid biomarkers versus Glasgow Coma Scale and Glasgow Outcome Scale in pediatric traumatic brain injury: the role of young age and inflicted injury. J Neurotrauma 2007;24:75-86.

-16 Berger RP, Ta'asan S, Rand A, Lokshin A, Kochanek P: Multiplex assessment of serum biomarker concentrations in well-appearing children with inflicted traumatic brain injury. Pediatr Res 2009;65:97-102.

-17 Kochanek PM, Berger RP, Bayır H, Wagner AK, Jenkins LW, Clark RS: Biomarkers of primary and evolving damage in traumatic and ischemic brain injury: diagnosis, prognosis, probing mechanisms, and therapeutic decision making. Curr Opin Crit Care 2008; 14:135-141.

-18 Berger RP, Dulani T, Adelson PD, Leventhal JM, Richichi R, Kochanek PM: Identification of inflicted traumatic brain injury in wellappearing infants using serum and cerebrospinal markers: a possible screening tool. Pediatrics 2006;117:325-332.

$>19$ Berger RP, Pierce MC, Wisniewski SR, Adelson PD, Clark RS, Ruppel RA, Kochanek PM: Neuron-specific enolase and S100B in cerebrospinal fluid after severe traumatic brain injury in infants and children. Pediatrics 2002;109:E31.

20 Berger RP, Kochanek PM: Urinary S100B concentrations are increased after brain injury in children: a preliminary study. Pediatr Crit Care Med 2006;7:557-561.

21 Aikman J, O’Steen B, Silver X, Torres R, Boslaugh S, Blackband S, Padgett K, Wang KK, Hayes R, Pineda J: Alpha-II-spectrin after controlled cortical impact in the immature rat brain. Dev Neurosci 2006;28:457-465.

22 Brophy GM, Pineda JA, Papa L, Lewis SB, Valadka AB, Hannay HJ, Heaton SC, Demery JA, Liu MC, Tepas JJ 3rd, Gabrielli A, Robicsek S, Wang KK, Robertson CS, Hayes RL: $\alpha I I-S p e c t r i n$ breakdown product cerebrospinal fluid exposure metrics suggest differences in cellular injury mechanisms after severe traumatic brain injury. J Neurotrauma 2009;26:471-479.

23 Bayır H, Tyurin VA, Tyurina YY, Viner R, Ritov V, Amoscato AA, Zhao Q, Zhang XJ, Janesko-Feldman KL, Alexander H, Basova LV, Clark RS, Kochanek PM, Kagan VE: Selective early cardiolipin peroxidation after traumatic brain injury: an oxidative lipidomics analysis. Ann Neurol 2007;62:154-169.

-24 Ichord RN, Naim M, Pollock AN, Nance ML, Margulies SS, Christian CW: Hypoxic-ischemic injury complicates inflicted and accidental traumatic brain injury in young children: the role of diffusion-weighted imaging. J Neurotrauma 2007;24:106-118.

25 Povlishock JT, Christman CW: The pathobiology of traumatically induced axonal injury in animals and humans: a review of current thoughts. J Neurotrauma 1995;12:555-564. Day KM, Merchant ML, Klein JB, Sullivan PG, Butterfield DA: Proteomic identification of oxidized mitochondrial proteins following experimental traumatic brain injury. J Neurotrauma 2007;24:772-789.

27 Sharma P, Benford B, Li ZZ, Ling GS: Role of pyruvate dehydrogenase complex in traumatic brain injury and measurement of pyruvate dehydrogenase enzyme by dipstick test. J Emerg Trauma Shock 2009;2:67-72.

28 Bayir H, Adelson PD, Wisniewski SR, Shore P, Lai Y, Brown D, Janesko-Feldman KL, Kagan VE, Kochanek PM: Therapeutic hypothermia preserves antioxidant defenses after severe traumatic brain injury in infants and children. Crit Care Med 2009;37:689-695.

29 Honda M, Tsuruta A, Kaneko T, Kasaoka S, Yagi T, Todani M, Fujita M, Izumi T, Maekawa T: Serum glial fibrillary acidic protein is a highly specific biomarker for traumatic brain injury in humans compared with S$100 \mathrm{~B}$ and neuron-specific enolase. J Trauma 2010;69:104-109.

30 Fraser DD, Close TE, Rose KL, Ward R, Mehl M, Farrell C, Lacroix J, Creery D, Kesselman $\mathrm{M}$, Stanimirovic D, Hutchison JS, for the Canadian Critical Care Translational Biology Group: Severe traumatic brain injury in children elevates glial fibrillary acidic protein in cerebrospinal fluid and serum. Pediatr Crit Care Med 2010, E-pub ahead of print.

31 Su E, Bell MJ, Wisniewski SR, Adelson PD, Janesko-Feldman KL, Salonia R, Clark RSB, Kochanek PM, Kagan VE, Bayır H: $\alpha$-Synuclein levels are elevated in cerebrospinal fluid following traumatic brain injury in infants and children: the effect of therapeutic hypothermia. Dev Neurosci 2010;32:385-395.

32 Berger RP, Bazaco MC, Wagner AK, Kochanek PM, Fabio A: Trajectory analysis of serum biomarker concentrations facilitates outcome prediction after pediatric traumatic and hypoxemic brain injury. Dev Neurosci 2010;32:396-405.

33 Vavilala MS, Muangman S, Waitayawinyu P, Roscigno C, Jaffe K, Mitchell P, Kirkness C, Zimmerman JJ, Ellenbogen R, Lam AM: Impaired cerebral autoregulation in infants and young children early after inflicted traumatic brain injury: a preliminary report. J Neurotrauma 2007;24:87-96.

34 Brady KM, Shaffner DH, Lee JK, Easley RB, Smielewski P, Czosnyka M, Jallo GI, Guerguerian AM: Continuous monitoring of cerebrovascular pressure reactivity after traumatic brain injury in children. Pediatrics 2009;124:e1205-e1212.

35 Stiefel MF, Udoetuk JD, Storm PB, Sutton LN, Kim H, Dominguez TE, Helfaer MA, Huh JW: Brain tissue oxygen monitoring in pediatric patients with severe traumatic brain injury. J Neurosurg 2006;105(suppl):281-286.

36 Hlatky R, Valadka AB, Gopinath SP, Robertson CS: Brain tissue oxygen tension response to induced hyperoxia reduced hypoperfused brain. J Neurosurg 2008;108:53-58.
- 37 Rosenthal G, Hemphill JC 3rd, Manley G: Brain tissue oxygen tension is more indicative of oxygen diffusion than oxygen delivery and metabolism in patients with traumatic brain injury. Crit Care Med 2009;37:379380.

38 Brain Trauma Foundation, American Association of Neurological Surgeons, Congress of Neurological Surgeons, Joint Section on Neurotrauma and Critical Care, AANS/ CNS, Bratton SL, Chestnut RM, Ghajar J, McConnel Hammond FF, Harris OA, Hartl R, Manley GT, Nemecek A, Newell DW, Rosenthal G, Schouten J, Shutter L, Timmons SD, Ullman JS, Videtta W, Wilberger JE, Wright DW: Guidelines for the management of severe traumatic brain injury. X. Brain oxygen monitoring and thresholds. J Neurotrauma 2007;24(suppl 1):S65-S70.

39 Vereczki V, Martin E, Rosenthal RE, Hof PR, Hoffman GE, Fiskum G: Normoxic resuscitation after cardiac arrest protects against hippocampal oxidative stress, metabolic dysfunction, and neuronal death. J Cereb Blood Flow Metab 2006;26:821-835.

40 Richards EM, Rosenthal RE, Kristian T, Fiskum G: Postischemic hyperoxia reduces hippocampal pyruvate dehydrogenase activity. Free Radic Biol Med 2006;40:1960-1970.

-41 Puccio AM, Hoffman LA, Bayır H, Zullo TG, Michael FR, Darby JM, Alexander S, Dixon CE, Okonkwo DO, Kochanek PM: Effect of short periods of normobaric hyperoxia on local brain tissue oxygenation and cerebrospinal fluid oxidative stress markers in severe traumatic brain injury. J Neurotrauma 2009;26:1241-1249.

42 Tsuru-Aoyagi K, Potts MB, Trivedi A, Pfankuch T, Raber J, Wendland M, Claus CP, Koh SE, Ferriero D, Noble-Haeusslein LJ: Glutathione peroxidase activity modulates recovery in the injured immature brain. Ann Neurol 2009;65:540-549.

43 Kilgannon JH, Jones AE, Shapiro NI, Angelos MG, Milcarek B, Hunter K, Parrillo JE, Trzeciak S, Emergency Medicine Shock Research Network (EMShockNet) Investigators: Association between arterial hyperoxia following resuscitation from cardiac arrest and in-hospital mortality. JAMA 2010;303: 2165-2171.

-44 Kochanek PM, Bayır H: Titrating oxygen during and after cardiopulmonary resuscitation. JAMA 2010;303:2190-2191.

45 Mehta A, Kochanek PM, Tyler-Kabara E, Adelson PD, Wisniewski SR, Berger RP, Sidoni MD, Bell RL, Clark RSB, Bell MJ: Relationship of intracranial pressure and cerebral perfusion pressure with outcome in young children after severe traumatic brain injury. Dev Neurosci 2010;32:413-419.

46 Keenan HT, Nocera M, Bratton SL: Frequency of intracranial pressure monitoring in infants and young toddlers with traumatic brain injury. Pediatr Crit Care Med 2005;6: 537-541. 
47 Chambers IR, Stobbart L, Jones PA, Kirkham FJ, Marsh M, Mendelow AD, Minns RA, Struthers S, Tasker RC: Age-related differences in intracranial pressure and cerebral perfusion pressure in the first 6 hours of monitoring after children's head injury: association with outcome. Childs Nerv Syst 2005;21:195-199.

-48 Levin HS, Aldrich EF, Saydjari C, Eisenberg HM, Foulkes MA, Bellefleur M, Luerssen TG, Jane JA, Marmarou A, Marshall LF, et al: Severe head injury in children: experience of the Traumatic Coma Data Bank. Neurosurgery 1992;31:435-443.

-49 Hutchison JS, Ward RE, Lacroix J, Hébert PC, Barnes MA, Bohn DJ, Dirks PB, Doucette S, Fergusson D, Gottesman R, Joffe AR, Kirpalani HM, Meyer PG, Morris KP, Moher D, Singh RN, Skippen PW, Hypothermia Pediatric Head Injury Trial Investigators and the Canadian Critical Care Trials Group: Hypothermia therapy after traumatic brain injury in children. N Engl J Med 2008;358: 2447-2456.

-50 Hutchison JS, Frndova H, Lo TM, Guerguerian A: Impact of hypotension and low cerebral perfusion pressure on outcomes in children treated with hypothermia therapy following severe traumatic brain injury: a post hoc analysis of the Hypothermia Pediatric Head Injury Trial. Dev Neurosci 2010;32:406-412.

- 51 Clifton GL, Miller ER, Choi SC, Levin HS, McCauley S, Smith KR Jr, Muizelaar JP, Wagner FC Jr, Marion DW, Luerssen TG, Chesnut RM, Schwartz M: Lack of effect of induction of hypothermia after acute brain injury. N Engl J Med 2001;344:556-563.

-52 Marion DW, Penrod LE, Kelsey SF, Obrist WD, Kochanek PM, Palmer AM, Wisniewski SR, DeKosky ST: Treatment of traumatic brain injury with moderate hypothermia. $\mathrm{N}$ Engl J Med 1997;336:540-546.

-53 Zhi D, Zhang S, Lin X: Study on therapeutic mechanism and clinical effect of mild hypothermia in patients with severe head injury. Surg Neurol 2003;59:381-385.

54 Jiang J, Yu M, Zhu C: Effect of long-term mild hypothermia therapy in patients with severe traumatic brain injury: 1-year followup review of 87 cases. J Neurosurg 2000;93: 546-549.

55 Clifton G: Hypothermia in neurotrauma (abstract). Proceedings of the 3rd International Hypothermia Symposium, Lund, 2009, p 8.

56 Maekawa T: Therapeutic mild hypothermia for severe traumatic brain injury in Japan: results of the RCT. Proceedings of the $3 \mathrm{rd}$ International Hypothermia Symposium, Lund, 2009, p 8.

- 57 Biswas AK, Bruce DA, Sklar FH, Bokovoy JL, Sommerauer JF: Treatment of acute traumatic brain injury in children with moderate hypothermia improves intracranial hypertension. Crit Care Med 2002;30:2742-2751.
58 Adelson PD, Ragheb J, Kanev P, Brockmeyer D, Beers SR, Brown SD, Cassidy LD, Chang Y, Levin H: Phase II clinical trial of moderate hypothermia after severe traumatic brain injury in children. Neurosurgery 2005;56:740754.

59 Gluckman PD, Wyatt JS, Azzopardi D, Ballard R, Edwards AD, Ferriero DM, Polin RA, Robertson CM, Thoresen M, Whitelaw A, Gunn AJ: Selective head cooling with mild systemic hypothermia after neonatal encephalopathy: multicentre randomised trial. Lancet 2005;365:663-670.

-60 Shankaran S, Laptook AR, Ehrenkranz RA, Tyson JE, McDonald SA, Donovan EF, Fanaroff AA, Poole WK, Wright LL, Higgins RD, Finer NN, Carlo WA, Duara S, Oh W, Cotten CM, Stevenson DK, Stoll BJ, Lemons JA, Guillet R, Jobe AH, National Institute of Child Health and Human Development Neonatal Research Network: Whole-body hypothermia for neonates with hypoxicischemic encephalopathy. N Engl J Med 2005;353:1574-1584.

61 Azzopardi DV, Strohm B, Edwards AD, Dyet L, Halliday HL, Juszczak E, Kapellou O, Levene M, Marlow N, Porter E, Thoresen M, Whitelaw A, Brocklehurst P, TOBY Study Group: Moderate hypothermia to treat perinatal asphyxia encephalopathy. N Engl J Med 2009;361:1349-1358.

62 Rutherford M, Ramenghi LA, Edwards AD, Brocklehurst $P$, Halliday $H$, Levene $M$, Strohm B, Thoresen M, Whitelaw A, Azzopardi D: Assessment of brain tissue injury after moderate hypothermia in neonates with hypoxic-ischemic encephalopathy: a nested substudy of a randomised controlled trial. Lancet Neurol 2010;9:39-45.

63 Kochanek PM, Tasker RC: Pediatric neurointensive care: 2008 update for the Roger's Textbook of Pediatric Intensive Care. Pediatr Crit Care Med 2009;10:517-523.

64 Kernie SG: Stem cells, neurogenesis and acquired brain injury. Proceedings of the Second joint Symposium of the International and National Neurotrauma Societies, Santa Barbara, 2009.

65 Covey MV, Jiang Y, Alli VV, Yang Z, Levison SW: Defining the critical period for neocortical neurogenesis after pediatric brain injury. Dev Neurosci 2010;32:488-498.

66 Wright J, Zhang G, Yu TS, Kernie SG: Agerelated changes in the oligodendrocyte progenitor pool influence brain remodeling after injury. Dev Neurosci 2010, E-pub ahead of print.

67 Scafidi S, Racz J, Hazelton J, McKenna MC, Fiskum G: Neuroprotection by acetyl-L-carnitine after traumatic injury to the immature rat brain. Dev Neurosci 2010;32:480-487.

68 Bogaert YE, Rosenthal RE, Fiskum G: Postischemic inhibition of cerebral cortex pyruvate dehydrogenase. Free Radic Biol Med 1994;16:811-820.
69 Robertson CL, Saraswati M, Fiskum G: Mitochondrial dysfunction early after traumatic brain injury in immature rats. J Neurochem 2007;101:1248-1257.

70 Duhaime AC: Large animal models of traumatic injury to the immature brain. Dev Neurosci 2006;28:380-387.

71 Naim MY, Friess S, Smith C, Ralston J, Ryall K, Helfaer MA, Margulies SS: Folic acid enhances early functional recovery in a piglet model of pediatric head injury. Dev Neurosci 2010;32:466-479.

72 Prins ML, Hales A, Reger M, Giza CC, Hovda DA: Repeat traumatic brain injury in the juvenile rat is associated with increased axonal injury and cognitive impairments. Dev Neurosci 2010;32:510-518.

73 Cernak I, Chang T, Ahmed FA, Cruz MI, Vink R, Stoica B, Faden A: Pathophysiological response to experimental diffuse brain trauma differs as a function of developmental age. Dev Neurosci 2010;32:442-453.

74 Babikian T, Prins ML, Cai Y, Barkhoudarian G, Hartonian I, Hovda DA, Giza CC: Molecular and physiological responses to juvenile TBI: focus on growth and metabolism. Dev Neurosci 2010;32:431-441.

75 Claus CP, Tsuru-Aoyagi K, Adwanikar H, Walker B, Whetstone W, Nobel-Haeusslein LJ: Age is a determinant of leukocyte infiltration and loss of cortical volume after traumatic brain injury. Dev Neurosci 2010; 32:454-465.

76 Tasker RC, Westland AG, White DK, Williams GB: Corpus callosum and inferior forebrain white mater microstructure are related to functional outcome from raised intracranial pressure in child traumatic brain injury. Dev Neurosci 2010, E-pub ahead of print.

77 di Gennaro JL, Mack CD, Malakouti A, Zimmerman JJ, Armstead W, Vavilala MS: Use and effect of vasopressors after pediatric traumatic brain injury. Dev Neurosci 2010;32:420-430.

78 Exo J, Kochanek PM, Adelson PD, Greene S, Clark RS, Bayır H, Wisniewski SR, Bell MJ: Intracranial pressure-monitoring systems in children with traumatic brain injury: combining therapeutic and diagnostic tools. Pediatr Crit Care Med 2010, E-pub ahead of print.

79 Baltagi SA, Shoykhet M, Felmet K, Kochanek PM, Bell MJ: Neurological sequelae of 2009 influenza A (H1N1) in children: a case series observed during a pandemic. Pediatr Crit Care Med 2010;11:179-184.

80 Bell MJ, Carpenter J, Au AK, Keating RF, Myseros JS, Yaun A, Weinstein S: Development of a pediatric neurocritical care service. Neurocrit Care 2009;10:4-10.

81 Glass HC, Bonifacio SL, Peloquin S, Shimotake T, Sehring S, Sun Y, Sullivan J, Rogers E, Barkovich AJ, Rowitch D, Ferriero DM: Neurocritical care for neonates. Neurocrit Care 2010;12:421-429. 